\title{
Isolation and Characterization of a Novel Arabidopsis thaliana Mutant Unable to Develop Wilt Symptoms After Inoculation with a Virulent Strain of Ralstonia solanacearum
}

\author{
Dong-Xin Feng, Laurent Deslandes, Harald Keller, Frédéric Revers, \\ Bruno Favery, Philippe Lecomte, Judith Hirsch, Jocelyne Olivier, and Yves Marco
}

\begin{abstract}
First, seventh, eighth, and ninth authors: Laboratoire des Interations Plantes-Microorganismes, CNRS/INRA, Chemin de Borde-Rouge, BP 27, Castanet-Tolosan, 31326, France; second author: Max-Planck-Institut für Züchtungsforschung, Abteilung Biochemie, Carl von Linné Weg 10, D-50829 Köln, Germany; third, fifth, and sixth authors: Institut National de la Recherche Agronomique, Station de Botanique et de Pathologie Végétale, BP 2078, 06606 Antibes Cedex, France; and fourth author: Virologie Végétale, IBVM-INRA Bordeaux-Aquitaine, Villenave d'Ornon, France.
\end{abstract}

Current address of D.-X. Feng: Institute of Vegetables and Flowers, CAAS, Beijing 100081, China.

Accepted for publication 4 November 2003.

\begin{abstract}
Feng, D.-X., Deslandes, L., Keller, H., Revers, F., Favery, B., Lecomte, P., Hirsch, J., Olivier, J., and Marco, Y. 2004. Isolation and characterization of a novel Arabidopsis thaliana mutant unable to develop wilt symptoms after inoculation with a virulent strain of Ralstonia solanacearum. Phytopathology 94:289-295.

To characterize host genes required for a compatible interaction, we identified a novel recessive Arabidopsis thaliana mutant, nwsl (no wilt symptoms), that failed to develop wilt symptoms in response to virulent strains of the phytopathogenic bacterium, Ralstonia solanacearum. The absence of wilting in nws 1 plants was not correlated with a cell death phenotype or a constitutive expression of salicylic acid-, jasmonic acid- or

ethylene-associated genes. In addition, this mutation, which conferred a symptomless phenotype in response to all the $R$. solanacearum strains tested, was highly specific to this pathogen, because $n w s 1$ responses to other plant pathogens, including oomycetes, nematodes, viruses, and other bacteria, were identical to those of wild-type Col-5 plants. Finally, the lack of disease development was shown to be different than RRS1-Rmediated resistance. The identification of mutants such as $n w s l$, that are unable to develop disease, should lead to the isolation of target host factors required for pathogen growth or fitness, or of factors modified by the invading microorganism to avoid or inactivate plant defense mechanisms, and should bring a better understanding of bacterial wilt diseases.
\end{abstract}

Plants protect themselves from pathogen attack by activation of a broad array of responses, which lead to the production of defensive compounds (29). Resistance $(R)$ genes constitute one of the most studied and efficient defense responses to infection by invading microorganisms. $R$ gene-mediated resistance (also termed gene-for-gene resistance) allows the detection of specific pathogen races through perception of pathogen-encoded avirulence proteins (Avr). Many plant $R$ genes conferring resistance to various pathogens have been cloned, and most of them typically encode leucine-rich repeat (LRR) receptors, classified in five major subfamilies (14). Pathogen recognition by these proteins activates defense responses via complex and intricate pathways requiring small signaling molecules such as salicylic acid, ethylene, and jasmonic acid (13). Numerous plant mutants, identified mostly in Arabidopsis thaliana, presenting enhanced susceptibility or enhanced resistance to various diseases, have been characterized, and have played a major role in deciphering the signaling events leading to resistance.

Although our knowledge of the molecular mechanisms underlying disease resistance has increased tremendously in the past few years, little is known about disease development and, in particular, about plant targets of microbial virulence factors. Plant metabolites, such as flavonoids, chemoattractants inducing nitrogen-fixing root nodule formation (31), and acetosyringone, a phe-

Corresponding author: Y. Marco; E-mail address: marco@toulouse.inra.fr

Publication no. P-2004-0112-03R

(c) 2004 The American Phytopathological Society nolic compound produced by wounded plant cells and involved in crown gall disease development caused by Agrobacterium tumefaciens (23), are among the better-studied examples of host susceptibility factors. Numerous pathogens also possess the ability to detect essential compounds present on leaf surfaces. For example, appressorium formation by Magnaporthe grisea is induced by cutine monomers (17).

Recently, several powdery mildew resistance (pmr) mutants affected in genes required for a compatible interaction between Arabidopsis thaliana and the biotrophic fungal pathogen, Erysiphe cichoracearum, have been identified $(39,40)$. Some of these mutants present characteristics that suggest they may be defective in host-susceptibility factors. (i) They do not constitutively express either the salicylic acid-associated $P R-1$ gene (34) or $P D F 1.2$, a marker for the ethylene- and jasmonic aciddependent pathway (30). These mutants differ, therefore, from the well-characterized lesions-simulating disease $(l s d)$, accelerated cell death $(a c d)$, and constitutive expresser of $P R$ genes $(c p r) A$. thaliana disease-resistance mutants. (ii) Their responses to other pathogens is similar to those of the wild-type plants. (iii) These mutations are pleiotropic, indicating that the corresponding genes play a role in plant growth and development. PMR6, one of the pmr-mutated genes, has been cloned and encodes a pectate lyaselike protein, suggesting a role in pectin degradation (39). The features of the $p m r$ mutants differentiate them from other mutants such as the barley mlo mutants that display durable, broad-spectrum resistance to most races of the biotrophic fungus Blumeria graminis f. sp. hordei (6). Mutation-induced recessive mlo alleles confer a leaf-lesion phenotype. MLO, localized in the plasma membrane via seven transmembrane helices, binds calmodulin 
(22) and probably acts as a negative regulator of plant defenses. Interestingly, mlo-mediated resistance is not effective against several other biotrophic and hemibiotrophic fungal pathogens. Another A. thaliana mutation for enhanced disease resistance, edr1, conferring resistance to Pseudomonas syringae, also confers resistance to the fungus E. cichoracearum, causes cell death at infection sites, and is associated with a strong induction of several defense responses after pathogen attack. The EDRl gene encodes a putative MAP (mitogen-activated protein) kinase that may negatively regulate salicylic acid-inducible defense responses (16).

To explain the lack of evidence for direct Avr-R interactions, a model, referred to as the guard model, recently has been proposed. It is based on the assumption that $\mathrm{R}$ proteins recognize matching Avr proteins only when the latter are complexed with their plant targets $(8,38)$. The identification of RIN4, a negative regulator of the plant basal immune response, whose binding or modification by two different Avr proteins, AvrB and AvrRpm1, leads to the activation of RPM1, the matching $\mathrm{R}$ protein, brings strong support to this model (25). The observation that a given $\mathrm{R}$ protein may recognize the activities of multiple effectors by detecting physiological changes in the cell recently has been strengthened by additional studies $(2,24)$. Thus, although our knowledge of the plant targets of pathogen virulence factors is increasing, it still remains rudimentary.

Ralstonia solanacearum is a gram-negative, soilborne pathogen that induces wilt disease development on more than 200 plant species (20). Although the complete genome of this important pathogen recently has been sequenced, and although major $R$. solanacearum pathogenicity determinants, the so-called hrp genes, have been studied extensively, the molecular mechanisms underlying resistance and susceptibility to wilt disease are still poorly understood. In tomato, resistance to $R$. solanacearum is controlled by several loci $(35,36)$, whereas in A. thaliana, it is monogenic and conferred by the $R R S I-R$ gene that encodes a novel $\mathrm{R}$ protein. This resistance is dependent upon salicylic acid and the NDR1 signaling pathway $(10,11)$. Recently, PopP2, the cognate Avr protein for RRS1-R, was identified and shown to interact with the R protein in the yeast two-hybrid system (9).

Although the development of wilt symptoms is independent of salicylic acid and jasmonic acid, ein2-1 ethylene-insensitive plants, in a susceptible Col-0 genetic background, present delayed symptoms in response to several virulent $R$. solanacearum strains, indicating that the ethylene signaling pathway plays an important role in the susceptible response of $A$. thaliana to $R$. solanacearum (21).

The objectives of this study were the identification and characterization of A. thaliana mutants altered in wilt disease develop- ment. The screening of 12,000 fast-neutron mutagenized glabrous Col-0 plants, normally susceptible to the $R$. solanacearum GMI1000 strain, led to the identification of $n w s 1$ (no wilt symptoms), a mutant resistant to all the strains of the pathogen tested. The genetic, phenotypic, and molecular characterization of this mutant is reported.

\section{MATERIALS AND METHODS}

Plant materials and bacterial inoculations. A. thaliana plants were grown and root inoculated with the various $R$. solanacearum strains as previously described (11). Alternatively, plants were infiltrated under vacuo for $2 \mathrm{~min}$ by immersing the foliage of plants still in their Jiffy pots (Jiffy France, Lyon, France) in a bacterial suspension containing $10^{7}$ bacteria $\mathrm{ml}^{-1}(11)$. Needleless syringe leaf inoculations were performed using bacterial suspendsions at a concentration of $10^{7}$ bacteria $\mathrm{ml}^{-1}$. Wilting of the susceptible Col-5 plants (a glabrous derivative of Col-0) was observed 4 to 8 days after inoculation. Pathogenicity tests were conducted until resistant $\mathrm{Nd}-1$ plants presented a yellowing of the older leaves (usually 12 to 16 days after inoculation). Col-0 mutagenized seed $\left(\mathrm{M}_{2}\right.$ generation) was purchased from Lehle Seeds (Round Rock, TX).

All the $R$. solanacearum strains used in this study were supplied by Christian Boucher and André Trigalet (Table 1). They were grown at $28^{\circ} \mathrm{C}$ in BGT medium (glucose [5 g/liter], triphenyltetrazolium chloride [50 mg/liter], and bactoagar [15 g/liter]) (4). The GMI1000 strain is a wild-type isolate virulent on tomato, which induces the hypersensitive response on tobacco. Disease symptoms were scored according to Deslandes et al. (11).

Internal bacterial populations in the aerial parts of plants, after root inoculation with a suspension of $10^{8}$ bacteria $\mathrm{ml}^{-1}$, were estimated in triplicate for each time point, according to the protocol of Deslandes et al. (11). Serial dilutions of bacteria present in the ground extracts of leaves were spread on solid BGT medium containing rifampicin $\left(50 \mu \mathrm{g} \mathrm{ml}^{-1}\right)$.

Virus infection. Cauliflower mosaic virus (CaMV; strain CabbB-JI, obtained from P. Yot, IBMP, Strasbourg, France) virulent on Col-5 was propagated in turnip (Brassica rapa), and Cucumber mosaic virus (CMV; R strain, from M. Jacquemond, INRA, Avignon, France) also virulent on Col-5, in Nicotiana tabacum. CaMV inoculum was prepared by grinding infected tissues in water. CMV inoculum was prepared by grinding symptomatic tissue in potassium phosphate buffer $(0.03 \mathrm{M}, \mathrm{pH}$ 7.0) at a $1: 4$ (wt/vol) tissue/buffer ratio with $0.2 \%$ diethyldithiocarbamate, $80 \mathrm{mg}$ of active charcoal, and $80 \mathrm{mg}$ of carborundum (400 mesh). Rosette leaves of 4- to 5-week-old A. thaliana plants were inoculated manually using a cotton-tip applicator. Viral

TABLE 1. Responses of Col-5, Nd-1, and nws1 Arabidopsis thaliana plants to inoculation by various Ralstonia solanacearum strains ${ }^{\mathrm{a}}$

\begin{tabular}{|c|c|c|c|c|c|c|c|}
\hline \multirow[b]{2}{*}{ Strain of $R$. solanacearum } & \multirow[b]{2}{*}{ Race } & \multirow[b]{2}{*}{ Biovar } & \multirow[b]{2}{*}{ Host plant } & \multirow[b]{2}{*}{ Geographic origin } & \multicolumn{3}{|c|}{ Response $^{\mathrm{b}}$} \\
\hline & & & & & $n w s 1$ & Nd-1 & Col-5 \\
\hline GMI 8089 & 4 & 4 & Ginger & Australia & $\mathrm{R}$ & $\mathrm{R}$ & $\mathrm{S}$ \\
\hline GMI 8092 & 4 & 4 & Ginger & Australia & $\mathrm{R}$ & $\mathrm{R}$ & $\mathrm{S}$ \\
\hline GMI 8083 & 1 & 3 & Tobacco & Australia & $\mathrm{R}$ & $\mathrm{R}$ & $\mathrm{S}$ \\
\hline GMI 1000 & 1 & 3 & Tomato & French Guyana & $\mathrm{R}$ & $\mathrm{R}$ & $\mathrm{S}$ \\
\hline GA4 & 1 & 3 & Eggplant & French West Indies & $\mathrm{R}$ & $\mathrm{R}$ & $\mathrm{S}$ \\
\hline GT4 & 1 & 3 & Tomato & French West Indies & $\mathrm{R}$ & $\mathrm{R}$ & $\mathrm{S}$ \\
\hline GT1 & 1 & 1 & Tomato & French West Indies & $\mathrm{R}$ & $\mathrm{S}$ & $\mathrm{S}$ \\
\hline $\mathrm{Rd}-15$ & 1 & 3 & Radish & Taiwan & $\mathrm{R}$ & $\mathrm{S}$ & $\mathrm{S}$ \\
\hline$\Delta$ PopP2 GMI1000 & 1 & 3 & Tomato & French Guyana & $\mathrm{R}$ & $\mathrm{S}$ & $\mathrm{S}$ \\
\hline GMI 8129 & 1 & 3 & Tomato & Australia & $\mathrm{R}$ & $\mathrm{R}$ & $\mathrm{R}$ \\
\hline GMI 8133 & 2 & 1 & Banana & Colombia & $\mathrm{R}$ & $\mathrm{R}$ & $\mathrm{R}$ \\
\hline GMI 8135 & 2 & 1 & Banana & Peru & $\mathrm{R}$ & $\mathrm{R}$ & $\mathrm{R}$ \\
\hline GMI 8142 & 3 & 2 & Potato & Australia & $\mathrm{R}$ & $\mathrm{R}$ & $\mathrm{R}$ \\
\hline GMI 8228 & 5 & ND & Mulberry & China & $\mathrm{R}$ & $\mathrm{R}$ & $\mathrm{R}$ \\
\hline
\end{tabular}

a Twenty plants of each line were root-inoculated with each strain $\left(10^{8}\right.$ bacteria $\left.\mathrm{ml}^{-1}\right)$. The experiment was repeated twice and similar results were obtained.

b $\mathrm{R}=$ resistance, $\mathrm{S}=$ susceptibility. 
infection in the nwsl mutant plants (five plants inoculated for each virus strain) was first evaluated for symptom expression by comparing it with the wild-type plants and confirmed by doubleantibody sandwich enzyme-linked immunosorbent assay (DASELISA) for CMV at 3 weeks postinoculation (wpi), or by reversetranscription polymerase chain reaction (RT-PCR) performed on inflorescence tissues for CaMV, at 4 wpi. RT-PCR was performed as described by Revers et al. (33) from semipurified total RNA preparations (3) with the primers 5'TAGTGATAATTTGCAGGTCGA and 5'GCGAAACCTAAGCTGTAGGTG (RT-PCR conditions: RT at $42^{\circ} \mathrm{C}$ for $45 \mathrm{~min}$ and $95^{\circ} \mathrm{C}$ for $3 \mathrm{~min}$; and PCR at $92^{\circ} \mathrm{C}$ for $20 \mathrm{~s}, 55^{\circ} \mathrm{C}$ for $20 \mathrm{~s}$, and $72^{\circ} \mathrm{C}$ for $1 \mathrm{~min}$ for 35 cycles).

Nematode infection. Seeds of Col-5 and nwsl plants were surface-sterilized and grown on Gamborg B5 medium (Sigma) containing $2 \%$ sucrose. Agar plates $(0.8 \%)$ were inclined at an angle of $60^{\circ}$ to allow the roots to grow along the surface. Threeweek-old seedlings (30 to 40 plants) were inoculated with 200 surface-sterilized second-stage juveniles of Meloidogyne incognita, a nematode virulent on Col-5 plants (Calissane isolate, France) per plant. The plates were kept at $20^{\circ} \mathrm{C}$ with a cycle of $16 \mathrm{~h}$ of light and $8 \mathrm{~h}$ of dark. Galls were counted 3 weeks after infection by visual scoring.

Oomycete infection. Conidiosporangia of Peronospora parasitica strains Noco2 and Emco5 were collected in water from $A$. thaliana cotyledons with profuse sporulation. For inoculations, the suspensions were adjusted to $4 \times 10^{4}$ spores $\mathrm{ml}^{-1}$, and sprayed to saturation onto 8-day-old A. thaliana seedlings. Inoculated plants were kept at high humidity at $16^{\circ} \mathrm{C}$ (photoperiod of $10 \mathrm{~h}$ with $120 \mu \mathrm{E} \mathrm{m}^{-2} \mathrm{~s}^{-1}$ ). As an indicator for resistance or susceptibility, sporulation on the cotyledons was examined 1 week after inoculation and the number of conidiophores determined for 10 individual plants. To determine the level of resistance or susceptibility, seedlings were collected individually 1 week after inoculation, placed into $200 \mu \mathrm{l}$ of water, and vortexed. The number of liberated spores per seedling was determined for five individual plants per treatment, using a hemocytometer.

RNA gel blot analysis. Total RNAs from $n w s l$ plants grown under high and low light conditions and from resistant $\mathrm{Nd}-1$ and susceptible Col-5 plants were isolated at different times after inoculation with strain GMI1000 and with an isogenic strain of GMI1000 deleted in its hrp gene cluster (32). They were isolated from frozen leaf material using the Extract-All solution, according to the recommendations of the manufacturer (Eurobio, France). For Northern blots, total RNA $(20 \mu \mathrm{g})$ was separated on $1 \%$ agarose gel, according to the protocol of McMaster and Carmichael (26), transferred to Nylon membranes (Hybond N+, Amersham Pharmacia Biotech, Buckinghamshire, England) in a $20 \times \mathrm{SSC}(1 \times \mathrm{SSC}$ is $0.15 \mathrm{M} \mathrm{NaCl}$ plus $0.015 \mathrm{M}$ sodium citrate) blotting solution ( $3 \mathrm{M} \mathrm{NaCl}, 0.3 \mathrm{M}$ sodium citrate, $\mathrm{pH} 7.0)$, and cross-linked to the filters using a UV Stratalinker 2400 (Stratagene, Ozyme, France).

Expressed sequence tag (EST) clones 92G1T7 (PR-3), 245P5T7 (PR-4), and 37F10T7 (PDF1.2), used for DNA probe synthesis, were ordered from the Arabidopsis Biological Resource Center. Plasmid DNAs were extracted using the Concert Rapid Plasmid Miniprep System (Invitrogen Life Technologies, San Diego, CA), according to the protocol provided by the manufacturer. The inserts were obtained after digestion with the appropriate restriction enzymes (SalI/NotI). PR-1 inserts (37) were obtained after digestion with $X h o \mathrm{I} / E c o$ RI. Prior to labeling, DNA inserts were gel purified using the JETSORB Gel Extraction Kit (GENOMED, Bad Oeynhausen, Germany). Labeling of the probes was performed by random priming using the Ready-To-Go kit (Amersham Pharmacia Biotech) with $\left(\alpha-{ }^{32} \mathrm{P}\right) \mathrm{dCTP}$, according to the instructions of the supplier. Membranes were prehybridized for $3 \mathrm{~h}$, and hybridized overnight at $65^{\circ} \mathrm{C}$ in $0.5 \mathrm{M} \mathrm{NaPO}_{4}(\mathrm{pH}$ 7.2), $25 \mathrm{mM}$ EDTA (pH 8.0), 0.1\% bovine serum albumine, 7\% sodium dodecyl sulfate (SDS), and heat-denatured salmon sperm
DNA at $0.1 \mathrm{mg} / \mathrm{ml}$. The membranes then were washed twice at $65^{\circ} \mathrm{C}$ in $2 \times \mathrm{SSC}, 0.1 \% \mathrm{SDS}$ for $10 \mathrm{~min}$, and once at the same temperature in $0.1 \times \mathrm{SSC}, 0.1 \% \mathrm{SDS}$, for $5 \mathrm{~min}$. Blots were exposed to autoradiogram film (Fuji Medical X-ray films). Equal loading was checked by RNA visualization of the membranes under UV.

\section{RESULTS}

Isolation of $n w s 1$ mutant. From a screen of $\approx 12,000$ fast neutron-mutagenized glabrous Col-0 plants performed under high light conditions, normally susceptible to strain GMI1000, only one mutant that did not develop visible wilt symptoms upon root inoculation with this strain (Fig. 1A) was isolated. This mutant, called $n w s 1$, did not exhibit spontaneous macroscopic lesions.

Genetic analysis of $n \boldsymbol{w s} 1$. $n w s \mathbf{1}$ was backcrossed to the wildtype Col-5 plant. Plants of the $\mathrm{F}_{1}$ progeny then were self-pollinated. The resulting $F_{2}$ progeny was inoculated with strain

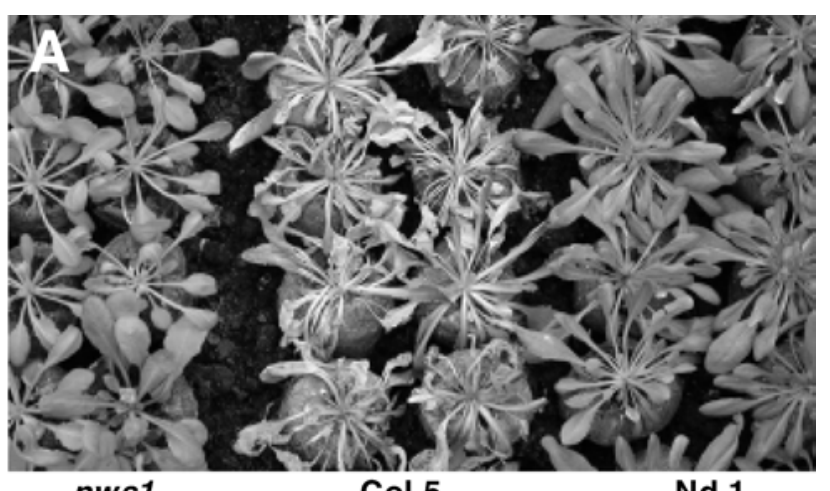

$$
\text { nws1 }
$$
Col-5 $\mathrm{Nd}-1$
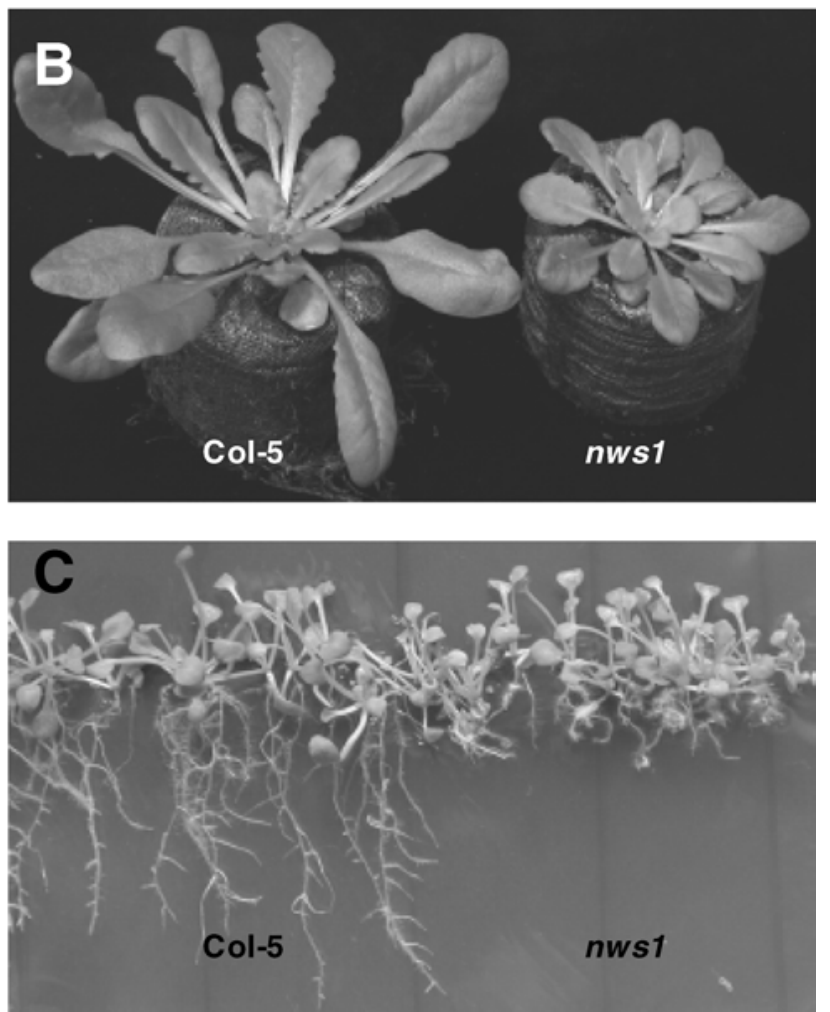

Fig. 1. Phenotype of $n w s 1$ plants. A, Responses of $n w s 1$, Col-5, and Nd-1 plants, 8 days after root inoculation with strain GMI1000 of Ralstonia solanacearum $\left(10^{8}\right.$ bacteria $\left.\mathrm{ml}^{-1}\right)$. B, nwsl plants grown under high light conditions $\left(240 \mu \mathrm{E} \mathrm{m}^{-2} \mathrm{~s}^{-1}\right)$ compared with Col-5 plants. C, Short root phenotype of 8-day-old $n w s 1$ plants grown under high light conditions on MS (11), a medium containing $10 \mathrm{~g}$ of sucrose, $5 \mathrm{~g}$ of Bacto agar, and $4.3 \mathrm{~g}$ of MS salts (Sigma Aldrich, France) per liter. 
GMI1000 and resistant plants were selected for subsequent backcrosses to the wild-type plant. This procedure was repeated three times before further characterization of the mutant.

Twenty-two plants from the $F_{1}$ progeny obtained from three independent crosses were tested for their response to strain GMI1000. All the tested plants were fully susceptible to the pathogen under high light conditions. The $\mathrm{F}_{2}$ progeny then were tested for their response to strain GMI1000. Resistance to this strain segregated in the $F_{2}$ progeny in a manner consistent with the existence of a single recessive gene (of 320 tested plants, 82 were resistant and 298 susceptible; $\chi^{2}=0.817$ for a $1: 3$ segregation, $0.5>P>0.25$ ). These results were confirmed by the analysis of the $F_{3}$ progeny from 15 resistant $F_{2}$ plants inoculated

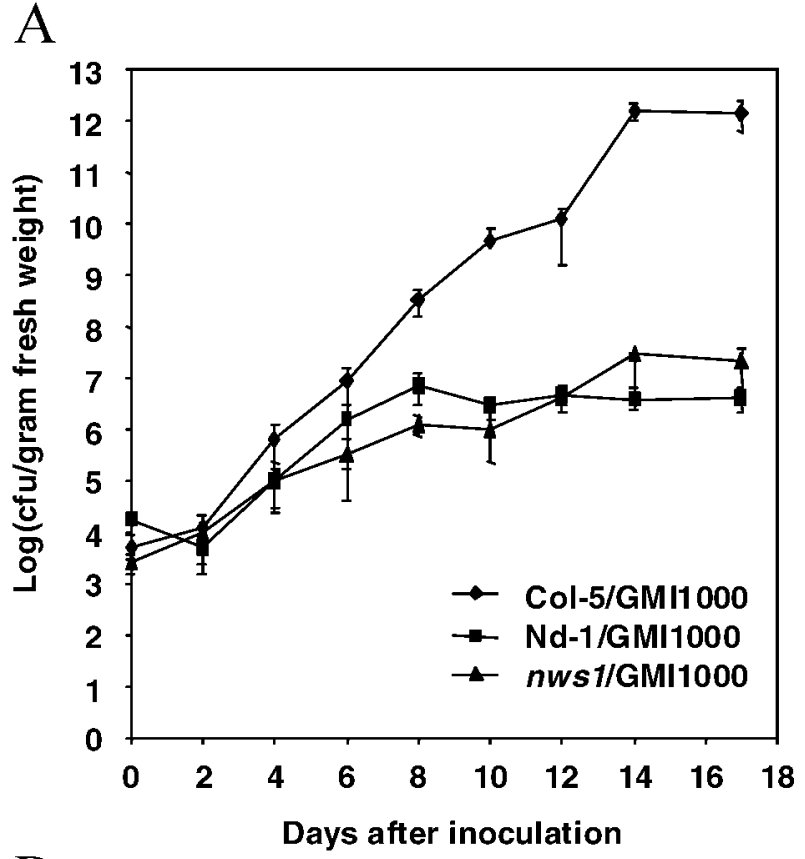

B

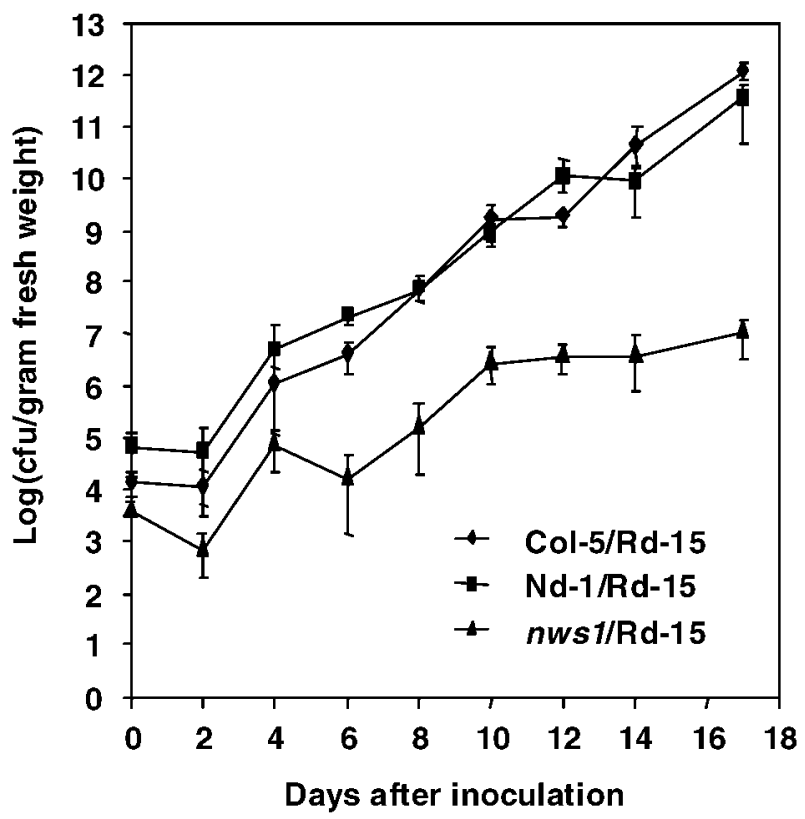

Fig. 2. Bacterial multiplication in leaves after root inoculation of Col-5, Nd-1, and nws 1 plants with Ralstonia solanacearum, A, strain GMI1000 (10 bacteria $\left.\mathrm{ml}^{-1}\right)$ and $\mathbf{B}$, strain $\mathrm{Rd}-15\left(10^{8}\right.$ bacteria $\left.\mathrm{ml}^{-1}\right)$. For each time point, triplicate assays were performed on three plants for each Arabidopsis thaliana accession or mutant line. This experiment was repeated twice, and reproducible results were obtained. Error bars represent standard deviations. with strain GMI1000. All the tested plants were resistant to the pathogen.

The nws1 mutation confers a pleiotropic phenotype. Apart from the absence of wilt symptom development, $n w s 1$ plants were smaller and greener than wild-type plants at high light intensities $\left(240 \mu \mathrm{E} \mathrm{m}^{-2} \mathrm{~s}^{-1}\right)$ (Fig. 1B). At lower light intensities $\left(115 \mu \mathrm{E} \mathrm{m}^{-2}\right.$ $\mathrm{s}^{-1}$ ), their phenotypes were indistinguishable from Col-5 plants and they became fully susceptible to the pathogen. Mutant plants also had shorter roots than the wild-type plants under both light conditions (Fig. 1C). To eliminate the possibility that the absence of wilt symptom development was due to a poor penetration of the bacteria within the root system, vacuum leaf infiltrations were performed. Eight days after inoculation with strain GMI1000, Col-5 plants were completely wilted, whereas no symptoms were visible on $n w s l$ and $\mathrm{Nd}-1$ resistant plants. Needleless syringe infiltrations also were performed, leading to the development of hypersensitive response (HR)-like lesions on nwsl leaves, whereas spreading chlorosis was observed on susceptible Col-5 plants (data not shown). These two observations indicated that the root phenotype of the mutant plants is not responsible for the absence of wilt symptoms. Under high light conditions, the dwarf plant phenotype as well as the short root phenotype co-segregated completely with the lack of wilt symptoms after inoculation with the pathogen through the three backcrosses and among the $320 \mathrm{~F}_{2}$ plants tested. Cell death probably is not the primary mechanism of resistance because no microlesion was visible on uninfected or root-inoculated $n w s 1$ plants.

Response of $n w s 1$ plants to different $R$. solanacearum strains. To determine whether the resistance caused by the $n w s l$ mutation is specific to strain GMI1000, different strains, encompassing the five $R$. solanacearum races and isolated originally from various plant species, were used to inoculate roots of $n w s 1$ plants. None of these strains induced wilt symptom development on nws 1 plants (Table 1). Of particular interest was the observation that some strains, such as Rd-15, as well as GT1, which are highly virulent on Nd-1 plants, did not induce disease development on $n w s 1$ plants. This result suggested that the absence of wilt symptom development in these mutant plants is different than the RRS1-R-mediated resistance (10). Inoculation of $n w s l$ plants with a GMI1000 strain deleted from PopP2, the cognate avirulence gene for $R R S 1-R$ (9), also was performed and did not lead to any detectable wilt symptom production, confirming these data.

Bacterial multiplication in nws1 plants. To test whether pathogen growth was affected in $n w s 1$ mutants, bacterial populations were estimated in $n w s l$ and in resistant and susceptible wild-type plants after inoculation with strain GMI1000, as well as with strain Rd-15. After root inoculation with strain GMI1000, the pathogen multiplied extensively in susceptible Col-5 plants, reaching densities of $\approx 10^{12}$ bacteria/g of fresh weight, five to six orders of magnitude higher than those found in resistant $\mathrm{Nd}-1$ plants. Bacterial levels in nws 1 plants were comparable with those detected in resistant Nd-1 plants (Fig. 2A). Inoculation with strain Rd-15 led to intense bacterial multiplication in Col-5 and Nd-1 plants, whereas the pathogen reached densities lower by five to six orders of magnitude in $n w s 1$ plants (Fig. 2B). These results illustrate that the mutation limits bacterial multiplication in planta.

nws 1 plants respond to other plant pathogens in a manner similar to wild-type plants. To determine whether the mutation is specific to $R$. solanacearum or whether it affects plant responses to other pathogens, nws 1 and wild-type plants were inoculated with different pathogens, including bacteria (Xanthomonas campestris pv. campestris strains 8004 [19] and Pseudomonas syringae pv. tomato strain DC3000, the latter either with or without the AvrRpml avirulence gene [5]), viruses (CaMV and CMV), a nematode (Meloidogyne incognita), and oomycetes such as Peronospora parasitica (strains Emco5 and Noco2). $n w s 1$ and 
Col-5 wild-type plants responded similarly to the HR-inducing $X$. campestris pv. campestris 147 strain and to the virulent $X$. campestris pv. campestris 8004 strain (data not shown). Similar results were obtained with the Pseudomonas syringae pv. tomato strains DC3000 and DC3000 AvrRpml (data not shown). The nws 1 mutation had no effect on the plant response either to CaMV and CMV (data not shown) or to $M$. incognita. In response to this latter pathogen, the average number of galls per plant was comparable in Col-5 and nws 1 plants (11.53 \pm 0.56 and $9.63 \pm$ 1.28 galls per plant, respectively). Finally, 8 days after inoculation, no significant difference was observed in conidiophore formation between Col-5 and mutant plants upon inoculation with the Peronospora parasitica Emco5 and Noco2 strains (Noco2, $28.1 \pm 8.6$ and $25.6 \pm 10.8$ conidiophores per cotyledon; and Emco5, $21.9 \pm 7.7$ and $24.1 \pm 6.8$ conidiophores per cotyledon on Col-5 and $n w s 1$ plants, respectively). Thus, all of the pathogens tested induced a similar response on wild-type and mutant plants, indicating that the $n w s l$-dependent resistance is specific to $R$. solanacearum.

The absence of wilt symptoms in nws 1 plants is not associated with an increased level of defense gene expression. To determine if the absence of disease symptom production in $n w s 1$ plants upon inoculation with $R$. solanacearum strains may be caused by the overproduction of defense-related proteins, as already reported for many $A$. thaliana mutants altered in their disease resistance response, transcript levels of different genes associated with defense responses were determined. The $P R-1$ gene was used as a marker for salicylic acid-dependent signaling pathways (34), and the $P D F 1.2, P R-3$, and $P R-4$ genes were chosen as markers of the ethylene- and jasmonic acid-dependent pathways (30). As shown previously (21), 4 days after inoculation, $P R-3$ transcripts started to accumulate in Col-5 plants and reached a high level, which was maintained afterward; $P R-4$ transcripts exhibited a similar pattern of expression, although their steady-state levels were lower than those detected with the $P R-3$ gene. Comparable results also were obtained in the case of $n w s 1$ plants grown under low light, which developed wilt symptoms. Very low levels of these two mRNAs were detected in resistant $\mathrm{Nd}-1$ and in nwsl plants grown under high light. A somewhat similar accumulation of PDF1.2 transcripts was observed, although steady-state levels of this mRNA were stronger in $n w s 1$ plants grown under low light than in Col-5 plants, for which the highest mRNA accumulation was observed 4 days after inoculation, and then decreased afterward (Fig. 3). The transcript steadystate levels of these three defense-related genes were low and comparable in noninfected Col-5 and nws 1 plants. PR-1 mRNAs were not detected (data not shown), suggesting that this gene is involved in neither disease development nor the establishment of resistance. The possibility that $P R-1$ mRNAs are expressed transiently and have not been detected in our experiment cannot be excluded. However, the observation that, in noninfected nws 1 plants, transcripts corresponding to this gene are undetectable, indicates that the absence of symptom development is not caused by a constitutive expression of $P R-1$. No reproducible signal was visible in Col-5 and nws 1 plants inoculated with the isogenic strain of GMI1000 deleted in its hrp gene cluster (data not shown).

\section{DISCUSSION}

Bacterial wilt caused by the phytopathogenic bacterium $R$. solanacearum is one of the most important plant diseases worldwide. Recently detected in Europe, this disease is endemic to all tropical and subtropical areas. Although our understanding of the role of $R$. solanacearum gene products involved in pathogenicity has increased tremendously in the past few years, very little is known about the plant gene products involved in the host responses to infection by this pathogen. In addition, most studies of plant-pathogen interactions have focused on resistance mechanisms.

Studies on disease, long considered to be a passive process, during which the plant was almost regarded as a substrate for the microorganism, were neglected completely. Recent findings, mostly in A. thaliana, demonstrated that an active metabolism of the plant is necessary for the appearance of symptoms. It is now well established, for instance, that ethylene insensitivity alters the susceptible response of various plants to different pathogens $(7,12)$, including $R$. solanacearum $(21)$. In fact, plant responses to virulent pathogens appear to be a composite of multiple signaling pathways $(27,28)$. However, the nature of the host components required for disease development, including susceptibility factors required for pathogen growth or fitness, targets of virulence factors, and negative regulators of defense responses, remains largely elusive. Most of the A. thaliana mutations that confer enhanced resistance to virulent strains of different pathogens, such as the $a c d, l s d, c p r, e d s$, and $e d r l$ mutations (18), are affected in components of the host defense response. This is in contrast to the pmr mutants, required for a compatible interaction between $A$. thaliana and the powdery mildew pathogen, E. cichoracearum. The pmr mutants exhibit an enhanced resistance that is not associated with a constitutive expression of known defense responses (40). The PMR6 gene has been cloned, and it encodes a pectate lyase-like protein, but its function in preventing pathogen development is still hypothetical (39). The observation that PMR6
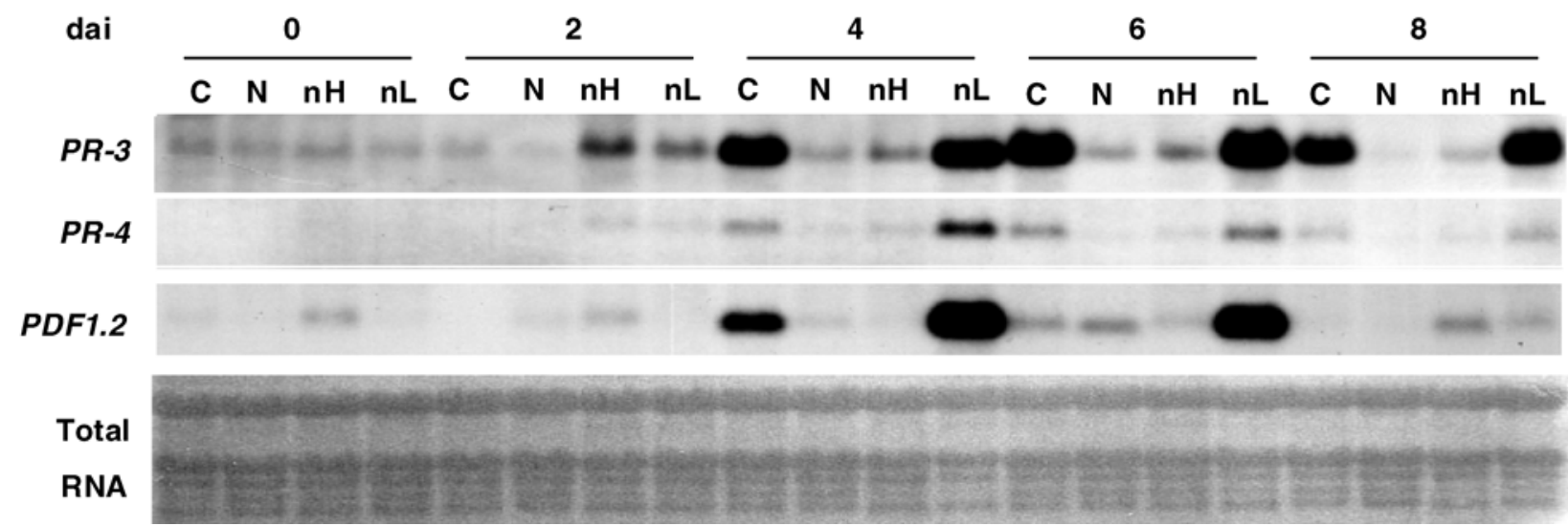

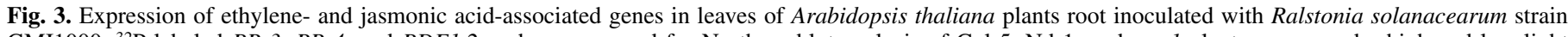

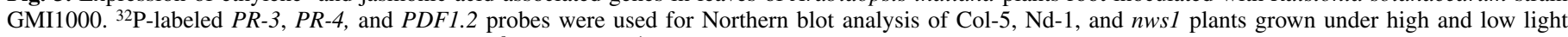

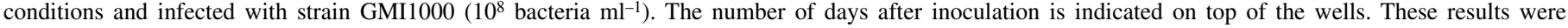

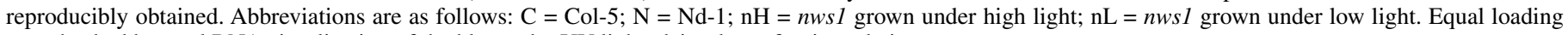
was checked by total RNA visualization of the blot under UV light; dai = days after inoculation. 
is required for diseases caused by powdery mildews, but not by unrelated pathogens, strongly suggests that it is a susceptibility factor.

We report the identification of a novel $A$. thaliana mutant that is unable to develop wilt symptoms in response to several strains of $R$. solanacearum. This pathogen is hemibiotrophic, and several bacterial effectors have been shown to be injected into plant cells via the type III secretion system. These effectors probably interact with host factors and may modify or suppress their activities. Considering these observations, we hypothesized that mutants exhibiting a reduced susceptibility could be identified. The screen used to isolate such mutants is destructive: plants presenting wilt symptoms die. This may explain, in part, the very low number of mutants which were isolated. In addition, several mutants which did not develop disease symptoms did not produce seed. We also observed some mutants in which wilting was strongly delayed, but which could not be further characterized because they eventually died without producing seed.

NWS1 presents features expected for genes encoding susceptibility factors. (i) The nws 1 mutation is recessive, suggesting that the altered gene is a host factor required for disease development. (ii) The nws1 mutation appears to be highly specific to $R$. solanacearum. Although it hinders disease development in response to all the strains of the bacterium tested, the response of the nws 1 plants to various other pathogens (oomycetes, bacteria, viruses, and nematodes) is comparable with that of the wild type. This feature is expected for a susceptibility factor, which theoretically should be a specific target of a given pathogen virulence effector, although the possibility that a host component is manipulated by several pathogens cannot be eliminated. (iii) The absence of disease development on $n w s 1$ plants is not correlated with an increased expression of defense genes. In noninfected plants, the transcript levels of molecular markers of the salicylic acid- and jasmonic acid- or ethylene-dependent pathways are identical to those of wild-type plants. Upon inoculation with the pathogen, $P R-1, P R-3, P R-4$, and $P D F 1.2$ mRNAs do not accumulate at higher levels in $n w s 1$ plants than in Col-5 plants. Additionally, no cell death lesions are visible at infection sites as occurs, for instance, for the edrl A. thaliana mutant (15).

The inability of $n w s 1$ plants to develop wilt symptoms is different than the resistance conferred by $R R S 1-R$, as demonstrated by two lines of evidence: these plants do not wilt upon inoculation either with strain $\mathrm{Rd}-15$, a strain virulent on $\mathrm{Nd}-1$, the $A$. thaliana ecotype carrying $R R S 1-R$ (10), or with the GMI1000 strain deleted of $P o p P 2$, the avirulence protein that matches the RRS1-R protein (9).

The nws 1 mutant displays phenotypic alterations such as conditional dwarfism and a short root system. This mutation is probably light-regulated because the phenotype of plants grown under low light is identical to that of wild-type plants and, under such conditions, their inability to develop disease symptoms is lost. The pmr3 mutant (40) also presents a dwarf phenotype that is not affected by light conditions although, under low light conditions, pmr3 plants are fully susceptible to powdery mildew pathogen. $n w s 1$ probably is not allelic to pmr3 because its dwarfism and its resistance to $R$. solanacearum are observed only under high light.

The NWS1 gene appears to be required for symptom development in response to all the strains tested, which include the five $R$. solanacearum races. This indicates that all these strains, whatever their origin and the plant from which they were isolated, require a common host component for full virulence. This factor may be involved in the binding of the bacteria to the plant cell wall. It has been demonstrated that expression of the R. solanacearum hrp genes, required both for causing disease symptoms on host plants and for eliciting the hypersensitive response on resistant and nonhost plants (4), is under the control of the $h r p B$ regulatory gene, whose expression is induced upon co-cultivation of bacteria and plant cell suspensions (1). The induction of the $\operatorname{hrpB}$ gene requires a physical contact between the bacterium and its target cell. Furthermore, the plant signal that triggers hrp gene expression upon $R$. solanacearum-plant cell contact is a nondiffusible component of the A. thaliana plant cell wall. NWS1 somehow may affect the synthesis of this signal, the attachment of bacteria to plant cells, or the injection of pathogenicity factors. Alternatively, different strains of the pathogen may have developed different strategies of plant colonization but may share an essential component for nutrition or fitness. Finally, the possibility that NWS1 is involved in the activation of novel and highly specific defense mechanisms, although rather improbable, cannot be completely ruled out.

The mapping and positional cloning of NWS1 should shed some light on the nature of this novel gene. The identification of susceptibility genes should bring some insights into the complex interplay between the plant and $R$. solanacearum, and eventually may lead to the elaboration of novel strategies to control wilt disease.

\section{ACKNOWLEDGMENTS}

We thank S. Bosc, C. Icher, and J.-L. Pariente for excellent technical assistance.

\section{LITERATURE CITED}

1. Aldon, D., Brito, B., Boucher, C., and Genin, S. 2000. A bacterial sensor of plant cell contact controls the transcriptional induction of Ralstonia solanacearum pathogenicity genes. EMBO J. 19:2304-2314.

2. Axtell, M. J., and Staskawicz, B. J. 2003. Initiation of RPS2-specified disease resistance in Arabidopsis is coupled to the AvrRpt2-directed elimination of RIN4. Cell 112:369-377.

3. Bertheau, Y., Frechon, D., Toth, I. K., and Hyman, L. J. 1998. DNA amplification by polymerase chain reaction (PCR). Pages 39-59 in: Methods for the Detection and Quantification of Erwinia carotovora subsp. atroseptica on Potatoes. M. C. M. Perombelon and J. M. van der Wolff, eds. Scottish Crop Research Institute, Invergowrie, Dundee, Scotland.

4. Boucher, C. A., Martinel, A., Trigalet, A. P., and Démery, D. A. 1985 Transposon mutagenesis of Pseudomonas solanacearum: Isolation of Tn5-induced avirulent mutants. J. Gen. Microbiol. 131:2449-2457.

5. Boyes, D. C., Nam, J., and Dangl, J. L. 1998. The Arabidopsis thaliana RPM1 disease resistance gene product is a peripheral plasma membrane protein that is degraded coincident with the hypersensitive response. Proc. Natl. Acad. Sci. USA 95:15849-15854.

6. Buschges, R., Hollricher, K., Panstruga, R., Simons, G., Wolter, M., Frijters, A., van Daelen, R., van der Lee, T., Diergaarde, P., Groenendijk, J., Topsch, S., Vos, P., Salamini, F., and Schulze-Lefert, P. 1997. The barley Mlo gene: A novel control element of plant pathogen resistance. Cell 88:695-705.

7. Ciardi, J. A., Tieman, D. M., Lund, S. T., Jones, J. B., Stall, R. E., and Klee, H. J. 2000. Response to Xanthomonas campestris pv. vesicatoria in tomato involves regulation of ethylene receptor gene expression. Plant Physiol. 123:81-92.

8. Dang1, J. L., and Jones, J. D. G. 2001. Plant pathogens and integrated defence responses to infection. Nature 411:826-833.

9. Deslandes, L., Olivier, J., Peters, N., Feng, D. X., Khounlotham, M., Boucher, C., Somssich, I., Genin, S., and Marco, Y. 2003. Direct physical interaction between RRS1-R, an Arabidopsis thaliana TIR-NBS-LRRWRKY protein conferring broad spectrum resistance to Ralstonia solanacearum and PopP2, a type III effector targeted to the plant nucleus. Proc. Natl. Acad. Sci. USA 100:8024-8029.

10. Deslandes, L., Olivier, J., Theulières, F., Hirsch, J., Feng, D. X., BittnerEddy, P., Beynon, J., and Marco, Y. 2002. Resistance to Ralstonia solanacearum in Arabidopsis thaliana is conferred by the recessive $R R S 1-R$ gene, a member of a novel family of resistance genes. Proc. Natl. Acad. Sci. USA 99:2404-2409.

11. Deslandes, L., Pileur, F., Liaubet, L., Camut, S., Can, C., Williams, K., Holub, E., Beynon, J., Arlat, M., and Marco, Y. 1998. Genetic characterization of RRS1, a recessive locus in Arabidopsis thaliana that confers resistance to the bacterial soilborne pathogen, Ralstonia solanacearum. Mol. Plant-Microbe Interact. 11:659-667.

12. Ellis, C., and Turner, J. G. 2001. The Arabidopsis mutant cev1 has constitutively active jasmonate and ethylene signal pathways and enhanced resistance to pathogens. Plant Cell 13:1025-1033. 
13. Feys, B., and Parker, J. E. 2000. Interplay of signalling pathways in plant disease resistance. Trends Genet. 16:449-455.

14. Fluhr, R. 2001. Sentinels of disease. Plant resistance genes. Plant Physiol. 127:1367-1374.

15. Frye, C. A., and Innes, R. W. 1998. An Arabidopsis mutant with enhanced resistance to powdery mildew. Plant Cell 10:947-956.

16. Frye, C. A., Tang, D., and Innes, R. W. 2001. Negative regulation of defense responses in plants by a conserved MAPKK kinase. Proc. Natl. Acad. Sci. USA 98:373-378.

17. Gilbert, R. D., Johnson, A. M., and Dean, R. A. 1996. Chemical signals for appressorium formation in the rice blast fungus Magnaporthe grisea. Physiol. Mol. Plant Pathol. 48:335-346.

18. Glazebrook, J. 2001. Genes controlling expression of defense responses in Arabidopsis. Curr. Opin. Plant Biol. 4:301-308.

19. Godard, F., Lummerzheim, M., Saindrenan, P., Balagué, C., and Roby, D. 2000. Hxc2, an Arabidopsis mutant with an altered hypersensitive response to Xanthomonas campestris pv. campestris. Plant J. 24:749-761.

20. Hayward, H. C. 1991. Biology and epidemiology of bacterial wilt caused by Pseudomonas solanacearum. Annu. Rev. Phytopathol. 29:65-87.

21. Hirsch, J., Deslandes, L., Feng, D. X., Balagué, C., and Marco, Y. 2002. Delayed symptom development in ein2-1, an Arabidopsis ethyleneinsensitive mutant, in response to bacterial wilt caused by Ralstonia solanacearum. Phytopathology 92:1142-1148.

22. Kim, M. C., Panstruga, R., Elliott, C., Muller, J., Devoto, A., Yoon, H. W., Park, H. C., Cho, M. J., and Schulze-Lefert, P. 2002. Calmodulin interacts with MLO protein to regulate defence against mildew in barley. Nature 416:447-451.

23. Lee, Y. W., Jin, S., Sim, W. S., and Nester, E. W. 1996. The sensing of plant signal molecules by Agrobacterium: Genetic evidence for direct recognition of phenolic inducers by the VirA protein. Gene 179:83-88.

24. Mackey, D., Belkhadir, Y., Alonso, J. M., Ecker, J. R., and Dangl, J. L. 2003. Arabidopsis RIN4 is a target of the type III virulence effector AvrRpt2 and modulates RPS2-mediated resistance. Cell 112:379-389.

25. Mackey, D., Holt, B. F., III, Wiig, A., and Dangl, J. L. 2002. RIN4 interacts with Pseudomonas syringae type III effector molecules and is required for RPM1-mediated resistance in Arabidopsis. Cell 108:743-754.

26. McMaster, G. K., and Carmichael, G. G. 1977. Analysis of single- and double-stranded nucleic acids on polyacrylamide and agarose gels by using glyoxal and acridine orange. Proc. Natl. Acad. Sci. USA 74:48354838 .

27. O'Donnell, P. J., Jones, J. B., Antoine, F. R., Ciardi, J., and Klee, H. J. 2001. Ethylene-dependent salicylic acid regulates an expanded cell death response to a plant pathogen. Plant J. 25:315-323.
28. O’Donnell, P. J., Schmelz, E. A., Moussatche, P., Lund, S.T., Jones, J. B. and Klee, H. J. 2003. Susceptible to intolerance-a range of hormonal actions in a susceptible Arabidopsis pathogen response. Plant J. 33:245-257.

29. Parker, J. E., Feys, B. J., ven der Bienzen, E. A., Noel, L., Aarts, N., Austin, M. J., Botella, M. A., Frost, L. N., Daniels, M. J., and Jones, J. D. G. 2000. Unravelling $R$ gene-mediated disease resistance pathways in Arabidopsis. Mol. Plant Pathol. 1:17-24.

30. Penninckx, I., Eggermont, K., Terras, F. R. G., Thomma, B., De Samblanx, G. W., Buchala, A., Metraux, J. P., Manners, J. M., and Broekaert, W. F. 1996. Pathogen-induced systemic activation of a plant defensin gene in Arabidopsis follows a salicylic acid-independent pathway. Plant Cell 8:2309-2323.

31. Perret, X., Staehelin, C., and Broughton, W. J. 2000. Molecular basis of symbiotic promiscuity. Microbiol. Mol. Biol. Rev. 64:180-201.

32. Prentki, P., and Krish, H. M. 1984. In vitro insertional mutagenesis with a selectable DNA fragment. Gene 29:303-313.

33. Revers, F., van der Vlugt, R. A., Souche, S., Lanneau, M., Lot, H., Candresse, T., and Le Gall, O. 1999. Nucleotide sequence of the $3^{\prime}$ terminal region of the genome of four lettuce mosaic virus isolates from Greece and Yemen. Arch. Virol. 144:1619-1626.

34. Ryals, J. A., Neuenschwander, U. H., Willits, M.G., Molina, A., Steiner, H. Y., and Hunt, M. D. 1996. Systemic acquired resistance. Plant Cell 8:1809-1819.

35. Thoquet, P., Olivier, J., Sperisen, C., Rogowsky, P., Laterrot, H., and Grimsley, N. 1996. Quantitative trait loci determining resistance to bacterial wilt in tomato cultivar Hawaii 7996. Mol. Plant-Microbe Interact. 9:826-836

36. Thoquet, P., Olivier, J., Sperisen, C., Rogowsky, P., Prior, P., Anaïs, G., Mangin, B., Bazin, B., Nazer, R., and Grimsley, N. 1996. Polygenic resistance of tomato plants to bacterial wilt in the French West Indies. Mol. Plant-Microbe Interact. 9:837-842.

37. Uknes, S., Mauch-Mani, B., Moyer, M., Potter, S., Williams, S., Dincher, S., Chandler, D., Slusarenko, A., Ward, E., and Ryals, J. 1992. Acquired resistance in Arabidopsis. Plant Cell 4:645-656.

38. Van der Biezen, E. A., and Jones, J. D. G. 1998. Plant disease-resistant proteins and the gene-for-gene concept. Trends Biochem. Sci. 23:454456.

39. Vogel, P. J., Raab, K. T., Schiff, C., and Somerville, C. S. 2002. PMR6, a pectate lyase-like gene required for powdery mildew susceptibility in Arabidopsis. Plant Cell 14:2095-2106.

40. Vogel, J., and Somerville, S. 2000. Isolation and characterization of powdery mildew-resistant Arabidopsis mutants. Proc. Natl. Acad. Sci. USA 97:1897-1902. 